\title{
Prophylactic Activation of Neuroprotective Stress Response Pathways by Dietary and Behavioral Manipulations
}

\author{
Mark P. Mattson, Wenzhen Duan, Ruqian Wan, and Zhihong Guo \\ Laboratory of Neurosciences, National Institute on Aging Gerontology Research Center, Baltimore, Maryland 21224
}

\begin{abstract}
Summary: It is well established that when most types of cells, including neurons, are exposed to a mild stress they increase their ability to resist more severe stress. This "preconditioning" phenomenon involves up-regulation of genes that encode cytoprotective proteins such as heat-shock proteins and growth factors. We found that a similar beneficial cellular stress response can be induced in neurons throughout the brain by a "meal-skipping" dietary restriction (DR) regimen in rats and mice. DR is effective in protecting neurons and improving functional outcome in models of stroke, Alzheimer's, Parkinson's and Huntington's diseases. DR induces an increase in the levels of brain-derived neurotrophic factor (BDNF) and heatshock proteins in neurons. DR also stimulates neurogenesis in
\end{abstract}

the hippocampus, and BDNF plays a role in this effect of DR. Physical exercise and environmental enrichment are two other manipulations that have been shown to induce BDNF expression in the brain, presumably because it is a mild cellular stress. When taken together with epidemiological and clinical studies in humans, the data from animal studies suggest that it may be possible to reduce the risk for age-related neurodegenerative disorders through dietary and behavioral modifications that act by promoting neuronal plasticity and survival. Key Words: Alzheimer's disease, BDNF, heat shock, neurogenesis, neurotrophic factors, oxidative stress, Parkinson's disease, serotonin, stroke.
In this article we consider the possible impact of dietary and behavioral interventions in improving the healthspan of the brain by focusing on four of the most prominent age-related neurological disorders. Ischemic stroke is the third leading cause of death $(200,000$ deaths per year in the United States) and is the leading neurological cause of disability (http://www.strokeassociation.org). More than 4 million Americans currently have Alzheimer's disease (AD) (http://www.alz.org) and more than 1.5 million have Parkinson's disease (PD) (http:// www.parkinson.org). As average life expectancy continues to increase, the numbers of victims of $A D$ and $P D$ is also increasing. Huntington's disease (HD) currently affects approximately 30,000 Americans and an additional 150,000 have a $50 \%$ risk of developing the disease (http://www.hdfoundation.org). Although each of these disorders may have a different principal cause, they share cellular and molecular abnormalities that are believed to be pivotal to the dysfunction and ultimate death of the

Address correspondence and reprint requests to Mark P. Mattson, Laboratory of Neurosciences, National Institute on Aging Gerontology Research Center, 5600 Nathan Shock Drive, Baltimore, MD 21224. E-mail: mattsonm@grc.nia.nih.gov. neurons. The abnormalities include increased oxidative stress, impaired energy metabolism, and disruption of cellular calcium homeostasis. ${ }^{1-4}$

\section{Neurodegenerative disorders result from insurmountable cellular stress}

Antecedent events in stroke include damage to cerebrovascular endothelial cells, atherosclerosis, and hypertension. The occlusion or rupture of a cerebral blood vessel causes hypoperfusion of the brain tissue supplied by the affected vessel, thereby subjecting neurons to hypoxia and hypoglycemia. Under such ischemic conditions neurons may die rapidly as the result of energy failure and complete disruption of cellular ion homeostasis, or they may undergo apoptosis or related forms of programmed cell death. ${ }^{5}$ The abilities of antioxidants, agents that increase cellular ATP levels, and drugs that stabilize cellular calcium homeostasis to reduce ischemic brain injury in animal models attest to the involvement of free radicals, energy impairment, and perturbed calcium regulation in stroke-induced neuronal death. ${ }^{6}$ In $\mathrm{AD}$, synaptic dysfunction and neuronal degeneration result from the aging process in combination with increased production and accumulation of neurotoxic forms of amyloid $\beta$-peptide and perturbed cellular calcium ho- 
meostasis. ${ }^{7}$ Membrane lipid peroxidation and engagement of apoptotic cascades may be pivotal events in AD. The degeneration of dopaminergic neurons in PD may result from age-related oxidative stress and impairment of mitochondrial ATP production, perhaps in combination with exposure to environmental toxins. ${ }^{8}$ The polyglutamine repeats in the mutant huntingtin protein may promote the death of striatal neurons by perturbing proteolytic pathways and/or by triggering apoptosis. ${ }^{9}$ Neuronal dysfunction and death have been ameliorated in animal and cell culture models of $\mathrm{AD}, \mathrm{PD}$, and $\mathrm{HD}$ by manipulations that reduce levels of oxidative stress and by agents that maintain ATP levels and ion homeostasis. ${ }^{10}$

\section{Dietary restriction: an intervention with powerful neuroprotective and neurorestorative actions}

The lifespans of all mammals studied to date can be significantly increased by reducing their caloric intake and/or meal frequency. The lifespans of rats and mice can be increased by up to $50 \%$ if such dietary restriction (DR) regimens are begun in young adults and maintained throughout life. ${ }^{11}$ DR reduces the incidence of age-related diseases such as cancer, cardiovascular disease, and diabetes in rodents and monkeys. ${ }^{11,12}$ The results of studies performed during the past 5 years suggest that a meal-skipping DR regimen can reduce the risk of each of the major neurodegenerative disorders described above. ${ }^{13-17}$ Rats maintained on DR for 2 to 4 months exhibit increased resistance to kainate-induced damage to hippocampal neurons and associated learning and memory deficits. ${ }^{13}$ Mice expressing a mutant form of presenilin-1 that causes early onset AD exhibit increased vulnerability of hippocampal neurons to excitotoxic injury, and DR counteracts this adverse effect of the presenilin-1 mutation. ${ }^{14}$ The vulnerability of substantia nigra dopaminergic neurons to 1-methyl-4-phenyl1,2,3,6-tetrahydropyridine toxicity was decreased, and motor function improved in mice that had been maintained on DR. ${ }^{15}$ Transgenic mice expressing mutant huntingtin driven by a prion promoter exhibit brain pathology, striatal and cortical degeneration, progressive motor dysfunction, and death. The degeneration of striatal neurons was attenuated, the onset of motor dysfunction was delayed, and lifespan was increased in huntingtin mutant mice when they were maintained on a DR diet. ${ }^{16}$ Finally, the ability of DR to improve outcome after a stroke was demonstrated in a rat model in which the middle cerebral artery was transiently occluded, resulting in damage to the cerebral cortex and striatum supplied by that artery and unilateral motor dysfunction. ${ }^{17}$ The data from animal models suggest that DR may prove beneficial in reducing the incidence and/or severity of the corresponding human neurodegenerative disorders.

The adult brain contains populations of cells in the subventricular zone and in the subgranular layer of the dentate gyrus of the hippocampus that are capable of dividing and then differentiating into neurons or glial cells. We discovered that DR can increase neurogenesis in the brains of rats and mice. ${ }^{18,19}$ Rats and mice that had been maintained for 3 months on DR were injected with the DNA precursor bromodeoxyuridine, were killed either 1 day or 3 to 4 weeks later, and numbers of bromodeoxyuridine-labeled cells in the dentate gyrus of the hippocampus were counted. At the 1-day time point there was no difference in numbers of labeled cells in animals on the DR diet compared to those on the control diet. However, at the 3- to 4-week time point there were significantly more labeled cells remaining in animals on DR, suggesting that DR promotes the survival of newly generated neural cells. By performing similar analyses in BDNF-deficient mice, we provided evidence that the increase in BDNF levels induced by DR plays an important role in promoting the survival of newly generated neurons. ${ }^{19}$ Other studies have shown that, in mice, DR can enhance performance of learning and memory tasks, ${ }^{20}$ which could also be mediated by BDNF. ${ }^{21}$

Epidemiological data suggest that individuals with a low calorie intake may have a reduced risk of stroke and neurodegenerative disorders. There is a strong correlation between per capita food consumption and risk for $\mathrm{AD}$ and stroke. ${ }^{22,23}$ Data from population-based casecontrol studies showed that individuals with the lowest daily calorie intakes had the lowest risk of $\mathrm{AD}$ and PD. ${ }^{24,25}$ In a population-based longitudinal prospective study of Nigerian families in which some members moved to the United States, it was shown that the incidence of $\mathrm{AD}$ among individuals living in the United States was increased compared to their relatives who remained in Nigeria. ${ }^{26}$ Although the environmental factors that increased risk of $\mathrm{AD}$ in industrialized countries are not known, one clear difference between the two environments is calorie intake, which is much higher in industrialized countries. Together, the epidemiological and experimental data provide strong evidence that DR can reduce risk of $\mathrm{AD}, \mathrm{PD}$, and stroke, three of the most devastating neurodegenerative conditions in the elderly.

The ability of DR to increase the resistance of neurons to oxidative, metabolic, excitotoxic, and apoptotic insults in animal models of neurodegenerative disorders clearly demonstrates an effect of DR on cellular stress resistance. We found that DR increases the expression of genes that encode proteins that promote neuronal survival and plasticity (Fig. 1). Thus, levels of heat-shock protein-70 (HSP-70) and glucose-regulated protein-78 (GRP-78) are increased in cortical, striatal, and hippocampal neurons of rats and mice maintained for several months on a dietary restriction feeding regimen. ${ }^{15,17-19}$ Other studies have shown that HSP-70 and GRP-78 can protect neurons against excitotoxic and oxidative injury, ${ }^{27,28}$ suggesting that increased levels con- 


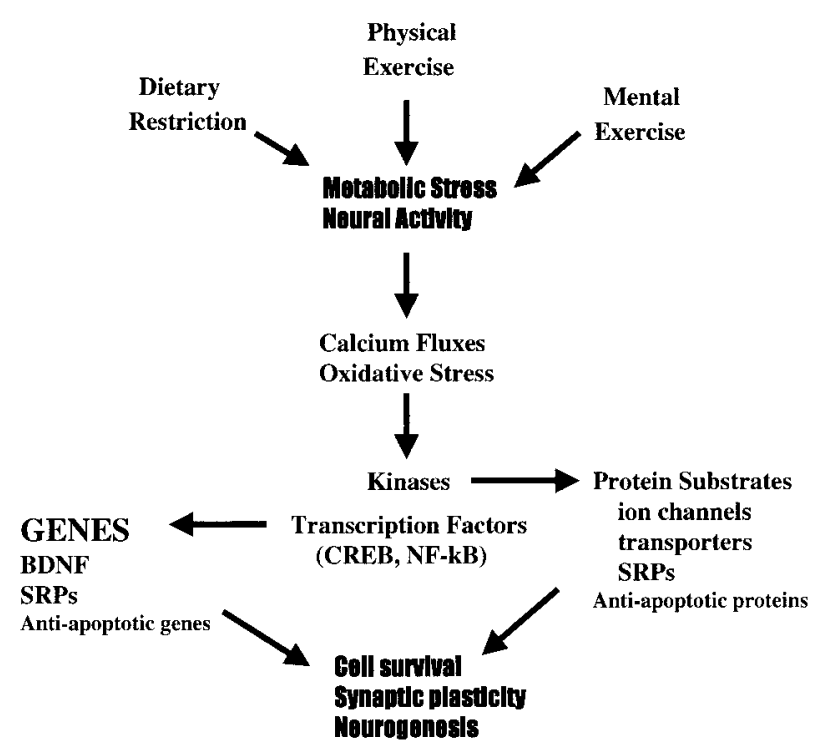

FIG. 1. Mechanisms underlying beneficial effects of dietary restriction, and physical and mental exercise on neurons. All three environmental factors impose a mild stress on neurons, which results from increased activity in neuronal circuits and/or metabolic stress. The cellular stress involves increased levels of intracellular calcium and reactive oxygen species which, in turn, activate kinases and transcription factors. The transcription factors induce the expression of genes that encode stress resistance proteins (SRPs), neurotrophic factors such as BDNF, and anti-apoptotic genes such as Bcl-2. Kinases may phosphorylate substrate proteins involved in maintenance of ion homeostasis, energy metabolism, and stress resistance.

tribute to the neuroprotective effect of dietary restriction. In addition to inducing stress-resistance protein chaperones, DR can induce the expression of several different neurotrophic factors in brain cells. Levels of BDNF are increased in neurons in the cerebral cortex, hippocampus, and striatum of rats and mice maintained on dietary restriction. ${ }^{16,18,19,29}$ It is known that BDNF can protect neurons in culture and in vivo against excitotoxic, metabolic, and apoptotic insults. ${ }^{30}$ Levels of nerve growth factor and ciliary neurotrophic factor are also increased by DR in one or more brain regions (unpublished data). ${ }^{29}$ Neurotrophic factors may protect neurons by stimulating the production of proteins that suppress oxidative stress (antioxidant enzymes and Bcl-2) and stabilize cellular calcium homeostasis (calcium-binding proteins and glutamate receptor subunits). ${ }^{1}$

The available data suggest that DR elicits a cellular stress response, although the exact nature of the stress is unclear; it might result from decreased energy (glucose) availability to the cells or from increased activity in neuronal circuits as the result of increased arousal due to hunger. That a cellular stress response is sufficient to account for the neuroprotective effects of DR is suggested by studies showing that administration of 2-deoxy-D-glucose (a non-metabolizable analog of glucose) to rats and mice fed ad libitum is neuroprotective. Animals given 2deoxy-D-glucose exhibit increased levels of protein chap- erones in brain cells and increased resistance of neurons to excitotoxic, oxidative, and ischemic injury. ${ }^{15,17,31}$

\section{Enhancement of neural plasticity and prophylaxis against neurodegenerative disorders by environmental enrichment and physical exercise}

When rats or mice are housed in complex environments or exercised on a regular basis, there are increases in the complexity of dendrites in cortical neurons, and increased numbers of synapses. ${ }^{32,33}$ Somatosensory deprivation reduces dendritic complexity in the neocortex of monkeys,${ }^{34}$ and psychosocial stress and other models of depression result in reduced neuritic and synaptic complexity. ${ }^{35}$ Environmental enrichment can also enhance recovery and regeneration of damaged neural circuits. For example, enriched rehabilitative therapy enhances dendritic growth and function recovery after focal ischemic brain injury. ${ }^{36}$ The molecular and cellular mechanisms responsible for beneficial or detrimental effects of different behaviors on the brain are beginning to be understood, and may involve changes in neurotrophic factor, neurotransmitter, and hormonal signaling pathways. The structural changes that occur in the neural circuits of animals housed in complex or impoverished environments have been associated with changes in levels of certain neurotrophic factors and with changes in performance on learning, and memory and motor function tasks. For example, environmental enrichment stimulates the production of BDNF in the hippocampus. ${ }^{37}$ The increased levels of BDNF likely play an important role in increased dendritic complexity and improved function in animals maintained in complex environments because BDNF overexpression is sufficient to increase dendritic complexity, ${ }^{38}$ and a BDNF-blocking antibody impairs learning and memory (Fig. 1). ${ }^{39}$

In regards to aging and age-related neurodegenerative disorders, the available data suggest that those behaviors that enhance dendritic complexity and synaptic plasticity also promote successful aging and decrease risk of neurodegenerative disorders. For example, there is an inverse relationship between educational level and risk for $\mathrm{AD}$; people with more education have a lower risk. ${ }^{40}$ Protection against $\mathrm{AD}$, and perhaps other age-related neurodegenerative disorders, likely begins during the first several decades of life, as is suggested by studies showing that individuals with the best linguistic abilities as young adults have a reduced risk for $\mathrm{AD} .^{41}$ Data from animal studies suggest that increased activity in neural circuits that results from intellectual activity stimulates the expression of genes that play a role in its neuroprotective effects. Levels of several different neurotrophic factors, including BDNF, are increased in the brains of animals maintained in complex environments, compared to animals maintained under usual housing conditions. $^{42,43}$ 


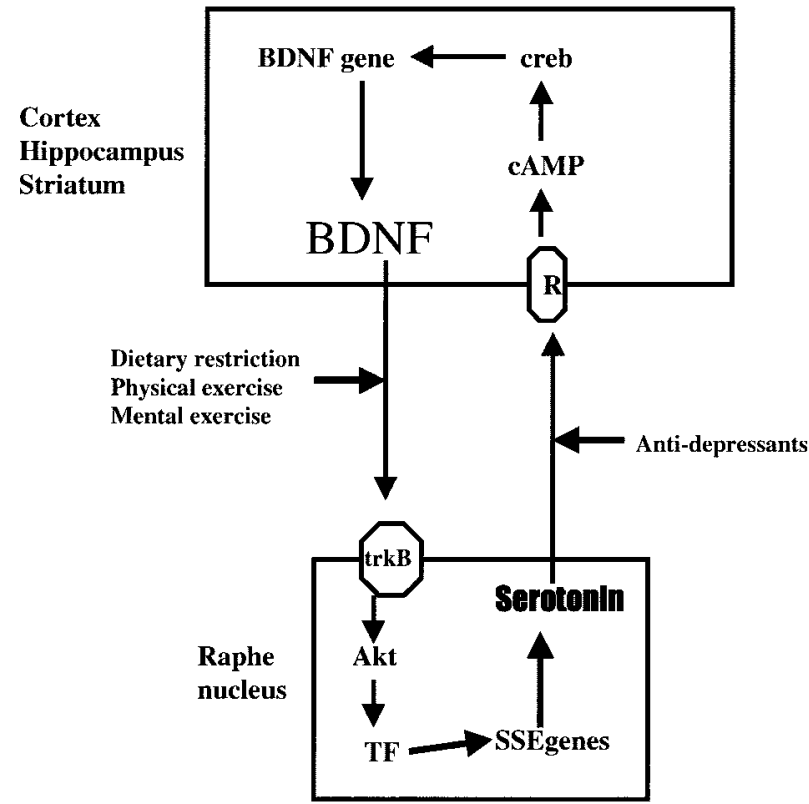

FIG. 2. Reciprocal interactions between serotonergic and BDNF signaling that likely play important roles in multiple responses of neurons to environmental factors. Serotonergic neurons in the raphe nucleus innervate neurons throughout the cerebral cortex, hippocampus, and striatum. Stimulation of serotonin receptors on the latter neurons results in production of cyclic AMP, activation of CREB and increased transcription of the BDNF gene. BDNF, in turn, can activate its high-affinity receptor trkB in serotonergic neurons, resulting in activation of Akt kinase and transcription factors (TF) and increased production of serotonin. By increasing the amount of serotonin in the synapse, antidepressants can induce BDNF production. Dietary restriction, and physical and mental exercise, up-regulate BDNF signaling and may thereby increase serotonergic signaling as well.

Regular physical exercise benefits the nervous system, as well as the musculoskeletal and cardiovascular systems. In humans, exercise may improve mood and cognition, ${ }^{44}$ and data suggest that regular exercise can also promote maintenance of cognitive function during aging. ${ }^{45}$ Rats that exercised regularly during a 9-week period exhibited improved performance in a learning and memory task and reduced levels of membrane lipid peroxidation and oxidative damage to DNA. ${ }^{46}$ When mice are provided access to a running wheel, the amount of neurogenesis in their hippocampi is increased and they exhibit improved performance in learning and memory tasks. ${ }^{47}$ Exercise results in an increase in the level of BDNF in the hippocampus, suggesting a role for BDNF in the beneficial effects of exercise on brain function and plasticity (Fig. 1). ${ }^{48}$ Exercise also increases levels of BDNF and neurotrophin-4, and high-affinity receptor trkB in neurons and oligodendrocytes in the spinal cord. ${ }^{49}$ Physical activity can also benefit the brain after injury. For example, functional outcome and structural plasticity in the motor cortex was enhanced in braininjured rats subjected to an exercise regimen. ${ }^{50}$ Exercise also improved outcome after traumatic brain injury in rats. ${ }^{51}$ Interestingly, exercise $(1 \mathrm{~km} /$ day on treadmill $)$ increases circulating IGF-1 and protects brain cells against excitotoxic injury; intravenous administration of IGF-1-blocking antibody abolished the neuroprotective effect of exercise. ${ }^{52}$ Research has also provided evidence that circulating IGF-1 plays an important role in the stimulation of hippocampal neurogenesis by physical exercise. ${ }^{53}$ Two additional effects of exercise on the brain that may contribute to its ability to promote neuronal plasticity and ward off neurodegenerative disease are enhancement of serotonergic signaling ${ }^{54}$ and stimulation of angiogenesis. ${ }^{55}$

\section{Pivotal mechanisms of environmental modulation of healthspan: BDNF, serotonin, and stress resistance proteins}

There are striking similarities in the effects of DR, physical exercise, and mental exercise on neurotrophic factor expression, cellular stress resistance, and neuronal plasticity, suggesting a shared mechanism underlying their beneficial effects in the brain. The effects of DR on gene expression and levels of various proteins strongly suggest that these types of beneficial diets (caloric restriction and meal-skipping/intermittent fasting) activate stress response pathways akin to those induced during the well-known phenomenon of preconditioning (ischemic preconditioning, sublethal heat-shock, etc.). ${ }^{56-58}$ The abilities of environmental enrichment and physical exercise to protect neurons in the brains of rats against ischemic injury ${ }^{59-61}$ is consistent with cellular stressresistance changes similar to those induced by DR. The mild stresses of DR, exercise, and mental gymnastics may stimulate calcium influx, which activates kinases and transcription factors that induce the expression of genes encoding proteins that promote cell survival, synaptic plasticity, and neurogenesis (Fig. 1). The BDNF gene is one prominent target of DR and physical and mental exercise that appears to mediate many of the beneficial effects of these dietary and behavioral stimuli. There is a reciprocal relationship between BDNF and serotonergic signaling, in which BDNF enhances serotonin production and release, ${ }^{62,63}$ and serotonergic signaling stimulates BDNF production (Fig. 2) ${ }^{64}$ Serotonin can activate receptors coupled to cyclic AMP production and cyclic AMP can induce BDNF expression by a cyclic AMP response element-binding protein (CREB)-mediated mechanism. ${ }^{64}$ Collectively, the emerging data suggest that activation of BDNF and serotonergic pathways may provide protection against a variety of neurodegenerative conditions, and possibly disorders linked to overeating and obesity, including type 2 diabetes and cardiovascular disease. ${ }^{65-68}$ 


\section{REFERENCES}

1. Mattson MP, Culmsee C, Yu ZF. Apoptotic and antiapoptotic mechanisms in stroke. Cell Tissue Res 301:173-187, 2000.

2. Mattson MP. Apoptosis in neurodegenerative disorders. Nat Rev Mol Cell Biol 1:120-129, 2000.

3. Cooper JM, Schapira AH. Mitochondrial dysfunction in neurodegeneration. J Bioenerg Biomembr 29:175-183, 1997.

4. Alexi T, Borlongan CV, Faull RL, Williams CE, Clark RG, Gluckman PD, Hughes PE. Neuroprotective strategies for basal ganglia degeneration: Parkinson's and Huntington's diseases. Prog Neurobiol 60:409-470, 2000.

5. Back T. Pathophysiology of the ischemic penumbra-revision of a concept. Cell Mol Neurobiol 18:621-638, 1998.

6. Mattson MP. Neuroprotective signal transduction: relevance to stroke. Neurosci Biobehav Rev 21:193-206, 1997.

7. Mattson MP, Pedersen WA, Duan W, Culmsee C, Camandola S. Cellular and molecular mechanisms underlying perturbed energy metabolism and neuronal degeneration in Alzheimer's and Parkinson's diseases. Ann NY Acad Sci 893:154-175, 1999.

8. Beal MF. Excitotoxicity and nitric oxide in Parkinson's disease pathogenesis. Ann Neurol 44:S110-S114, 1998.

9. Mattson MP. Accomplices to neuronal death. Nature 415:377-379, 2002.

10. Mattson MP. Excitotoxic and excitoprotective mechanisms: abundant targets for the prevention and treatment of neurodegenerative disorders. Neuromolecular Med 3:65-94, 2003.

11. Weindruch R, Sohal RS. Seminars in medicine of the Beth Israel Deaconess Medical Center. Caloric intake and aging. $N$ Engl J Med337:986-994, 1997.

12. Mattison JA, Lane MA, Roth GS, Ingram DK. Calorie restriction in rhesus monkeys. Exp Gerontol 38:35-46, 2003.

13. Bruce-Keller AJ, Umberger G, McFall R, Mattson MP. Food restriction reduces brain damage and improves behavioral outcome following excitotoxic and metabolic insults. Ann Neurol 45:8-15, 1999.

14. Zhu H, Guo Q, Mattson MP. Dietary restriction protects hippocampal neurons against the death-promoting action of a presenilin-1 mutation. Brain Res 842:224-229, 1999.

15. Duan W, Mattson MP. Dietary restriction and 2-deoxyglucose administration improve behavioral outcome and reduce degeneration of dopaminergic neurons in models of Parkinson's disease. J Neurosci Res 57:195-206, 1999.

16. Duan W, Guo Z, Jiang H, Ware M, Li SJ, Mattson MP. Dietary restriction normalizes glucose metabolism and BDNF levels, slows disease progression and increases survival in huntingtin mutant mice. Proc Natl Acad Sci USA 100:2911-2916, 2003.

17. Yu ZF, Mattson MP. Dietary restriction and 2-deoxyglucose administration reduce focal ischemic brain damage and improve behavioral outcome: evidence for a preconditioning mechanism. J Neurosci Res 57:830-839, 1999.

18. Lee J, Duan W, Long JM, Ingram DK, Mattson MP. Dietary restriction increases the number of newly generated neural cells, and induces BDNF expression, in the dentate gyrus of rats. $J \mathrm{Mol}$ Neurosci 15:99-108, 2000.

19. Lee J, Duan W, Mattson MP. Evidence that brain-derived neurotrophic factor is required for basal neurogenesis and mediates, in part, the enhancement of neurogenesis by dietary restriction in the hippocampus of adult mice. J Neurochem 82:1367-1375, 2002.

20. Ingram DK, Weindruch R, Spangler EL, Freeman JR, Walford RL. Dietary restriction benefits learning and motor performance of aged mice. J Gerontol 42:78-81, 1987.

21. Yamada K, Mizuno M, Nabeshima T. Role for brain-derived neurotrophic factor in learning and memory. Life Sci 70:735-744, 2002.

22. Grant WB, Campbell A, Itzhaki RF, Savory J. The significance of environmental factors in the etiology of Alzheimer's disease. $J$ Alzheimers Dis 4:179-189, 2002.

23. Barrett-Connor E. Obesity, hypertension and stroke. Clin Exp Hypertens A 12:769-782, 1990.

24. Luchsinger JA, Tang MX, Shea S, Mayeux R. Caloric intake and the risk of Alzheimer disease. Arch Neurol 59:1258-1263, 2002.
25. Logroscino G, Marder K, Cote L, Tang MX, Shea S, Mayeux R. Dietary lipids and antioxidants in Parkinson's disease: a population-based, case-control study. Ann Neurol 39:89-94, 1996.

26. Hendrie HC, Ogunniyi A, Hall KS, Baiyewu O, Unverzagt FW, Gureje O, Gao S, Evans RM, Ogunseyinde AO, Adeyinka AO, Musick B, Hui SL. Incidence of dementia and Alzheimer disease in 2 communities: Yoruba residing in Ibadan, Nigeria, and African Americans residing in Indianapolis, Indiana. JAMA 285:739-747, 2001.

27. Lowenstein DH, Chan PH, Miles MF. The stress protein response in cultured neurons: characterization and evidence for a protective role in excitotoxicity. Neuron 7:1053-1060, 1991.

28. Yu Z, Luo H, Fu W, Mattson MP. The endoplasmic reticulum stress-responsive protein GRP78 protects neurons against excitotoxicity and apoptosis: suppression of oxidative stress and stabilization of calcium homeostasis. Exp Neurol 155:302-314, 1999.

29. Duan W, Guo Z, Mattson MP. Brain-derived neurotrophic factor mediates an excitoprotective effect of dietary restriction in mice. J Neurochem 76:619-626, 2001.

30. Mattson MP, Cheng B, Smith-Swintosky VL. Mechanisms of neurotrophic factor protection against calcium- and free radical-mediated excitotoxic injury: implications for treating neurodegenerative disorders. Exp Neurol 124:89-95, 1993.

31. Lee J, Bruce-Keller AJ, Kruman Y, Chan SL, Mattson MP. 2-Deoxy-D-glucose protects hippocampal neurons against excitotoxic and oxidative injury: evidence for the involvement of stress proteins. J Neurosci Res 57:48-61, 1999.

32. Comery TA, Stamoudis CX, Irwin SA, Greenough WT. Increased density of multiple-head dendritic spines on medium-sized spiny neurons of the striatum in rats reared in a complex environment. Neurobiol Learn Mem 66:93-96, 1996.

33. Greer ER, Diamond MC, Murphy GM Jr. Increased branching of basal dendrites on pyramidal neurons in the occipital cortex of homozygous Brattleboro rats in standard and enriched environmental conditions: a Golgi study. Exp Neurol 76:254-262, 1982.

34. Bryan GK, Riesen AH. Deprived somatosensory-motor experience in stumptailed monkey neocortex: dendritic spine density and dendritic branching of layer IIIB pyramidal cells. J Comp Neurol286: 208-217, 1989.

35. McEwen BS, Magarinos AM, Reagan LP. Studies of hormone action in the hippocampal formation: possible relevance to depression and diabetes. J Psychosom Res 53:883-890, 2002.

36. Biernaskie J, Corbett D. Enriched rehabilitative training promotes improved forelimb motor function and enhanced dendritic growth after focal ischemic injury. J Neurosci 21:5272-5280, 2001.

37. Falkenberg T, Mohammed AK, Henriksson B, Persson H, Winblad $\mathrm{B}$, Lindefors N. Increased expression of brain-derived neurotrophic factor mRNA in rat hippocampus is associated with improved spatial memory and enriched environment. Neurosci Lett 138:153156, 1992.

38. Tolwani RJ, Buckmaster PS, Varma S, Cosgaya JM, Wu Y, Suri C, Shooter EM. BDNF overexpression increases dendrite complexity in hippocampal dentate gyrus. Neuroscience 114:795-805, 2002.

39. Alonso M, Vianna MR, Depino AM, Mello e Souza T, Pereira P, Szapiro G, Viola H, Pitossi F, Izquierdo I, Medina JH. BDNFtriggered events in the rat hippocampus are required for both shortand long-term memory formation. Hippocampus 12:551-560, 2002.

40. Katzman R. Education and the prevalence of dementia and Alzheimer's disease. Neurology 43:13-20, 1993.

41. Snowdon DA, Kemper SJ, Mortimer JA, Greiner LH, Wekstein DR, Markesbery WR. Linguistic ability in early life and cognitive function and Alzheimer's disease in late life. Findings from the Nun Study. JAMA 275:528-532, 1996.

42. Pham TM, Winblad B, Granholm AC, Mohammed AH. Environmental influences on brain neurotrophins in rats. Pharmacol Biochem Behav 73:167-175, 2002.

43. Zhao LR, Risedal A, Wojcik A, Hejzlar J, Johansson BB, Kokaia Z. Enriched environment influences brain-derived neurotrophic factor levels in rat forebrain after focal stroke. Neurosci Lett 305: 169-172, 2001.

44. de Coverley Veale DM. Exercise and mental health. Acta Psychiatr Scand 76:113-120, 1987. 
45. Chodzko-Zajko WJ, Moore KA. Physical fitness and cognitive functioning in aging. Exerc Sport Sci Rev 22:195-220, 1994.

46. Radak Z, Kaneko T, Tahara S, Nakamoto H, Pucsok J, Sasvari M, Nyakas C, Goto S. Regular exercise improves cognitive function and decreases oxidative damage in rat brain. Neurochem Int 38: $17-23,2001$.

47. van Praag H, Kempermann G, Gage FH. Running increases cell proliferation and neurogenesis in the adult mouse dentate gyrus. Nat Neurosci 2:266-270, 1999.

48. Russo-Neustadt AA, Beard RC, Huang YM, Cotman CW. Physical activity and antidepressant treatment potentiate the expression of specific brain-derived neurotrophic factor transcripts in the rat hippocampus. Neuroscience 101:305-312, 2000.

49. Skup M, Dwornik A, Macias M, Sulejczak D, Wiater M, Czarkowska-Bauch J. Long-term locomotor training up-regulates $\operatorname{TrkB}(\mathrm{FL})$ receptor-like proteins, brain-derived neurotrophic factor, and neurotrophin 4 with different topographies of expression in oligodendroglia and neurons in the spinal cord. Exp Neurol 176: 289-307, 2002.

50. Jones TA, Chu CJ, Grande LA, Gregory AD. Motor skills training enhances lesion-induced structural plasticity in the motor cortex of adult rats. J Neurosci 19:10153-10163, 1999.

51. Hicks RR, Boggs A, Leider D, Kraemer P, Brown R, Scheff SW, Seroogy KB. Effects of exercise following lateral fluid percussion brain injury in rats. Restor Neurol Neurosci 12:41-47, 1998.

52. Carro E, Trejo JL, Busiguina S, Torres-Aleman I. Circulating insulin-like growth factor I mediates the protective effects of physical exercise against brain insults of different etiology and anatomy. J Neurosci 21:5678-5684, 2001.

53. Trejo JL, Carro E, Torres-Aleman I. Circulating insulin-like growth factor I mediates exercise-induced increases in the number of new neurons in the adult hippocampus. $J$ Neurosci 21:16281634,2001

54. Lim BV, Jang MH, Shin MC, Kim HB, Kim YJ, Kim YP, Chung JH, Kim H, Shin MS, Kim SS, Kim EH, Kim CJ. Caffeine inhibits exercise-induced increase in tryptophan hydroxylase expression in dorsal and median raphe of Sprague-Dawley rats. Neurosci Lett308:25-28, 2001.

55. Swain RA, Harris AB, Wiener EC, Dutka MV, Morris HD, Theien BE, Konda S, Engberg K, Lauterbur PC, Greenough WT. Prolonged exercise induces angiogenesis and increases cerebral blood volume in primary motor cortex of the rat. Neuroscience 117: 1037-1046, 2003.

56. Prolla T, Mattson MP. Molecular mechanisms of brain aging and neurodegenerative disorders: lessons from dietary restriction. Trends Neurosci 24:S21-S31, 2001.
57. Anson RM, Guo Z, De Cabo R, Iyun T, Rios M, Hagepanos A, Ingram DK, Lane MA, Mattson MP. Intermittent fasting dissociates beneficial effects of dietary restriction on glucose metabolism and neuronal resistance to injury from calorie intake. Proc Natl Acad Sci USA 100:6216-6220, 2003.

58. Guo Z, Ersoz A, Butterfield DA, Mattson MP. Beneficial effects of dietary restriction on cerebral cortical synaptic terminals: preservation of glucose and glutamate transport and mitochondrial function after exposure to amyloid $\beta$-peptide, iron, and 3-nitropropionic acid. $J$ Neurochem 75:314-320, 2000.

59. Yang YR, Wang RY, Wang PS. Early and late treadmill training after focal brain ischemia in rats. Neurosci Lett 339:91-94, 2003.

60. Ohlsson AL, Johansson BB. Environment influences functional outcome of cerebral infarction in rats. Stroke 26:644-649, 1995.

61. Chou IC, Trakht T, Signori C, Smith J, Felt BT, Vazquez DM, Barks JD. Behavioral/environmental intervention improves learning after cerebral hypoxia-ischemia in rats. Stroke 32:2192-2197, 2001.

62. Rumajogee P, Madeira A, Verge D, Hamon M, Miquel MC. Upregulation of the neuronal serotoninergic phenotype in vitro: BDNF and cAMP share trkB-dependent mechanisms. $J$ Neurochem 83:1525-1528, 2002.

63. Goggi J, Pullar IA, Carney SL, Bradford HF. Modulation of neurotransmitter release induced by brain-derived neurotrophic factor in rat brain striatal slices in vitro. Brain Res 941:34-42, 2002.

64. Conti AC, Cryan JF, Dalvi A, Lucki I, Blendy JA. cAMP response element-binding protein is essential for the up-regulation of brainderived neurotrophic factor transcription, but not the behavioral or endocrine responses to antidepressant drugs. $J$ Neurosci 22:32623268, 2002.

65. Pelleymounter MA, Cullen MJ, Wellman CL. Characteristics of BDNF-induced weight loss. Exp Neurol 131:229-238, 1995.

66. Duan W, Guo Z, Jiang H, Ware M, Mattson MP. Reversal of behavioral and metabolic abnormalities, and insulin resistance syndrome, by dietary restriction in mice deficient in brain-derived neurotrophic factor. Endocrinology 144:2446-2453, 2003.

67. Wan R, Camandola S, Mattson MP. Intermittent fasting and dietary supplementation with 2-deoxy-D-glucose improve functional and metabolic cardiovascular risk factors in rats. FASEB $J 17$ : 1133-1134, 2003.

68. Wan R, Camandola S, Mattson MP. Intermittent fasting improves cardiovascular and neuroendocrine responses to stress. $J$ Nutrition 133:1921-1929, 2003. 